Subscriber access provided by Caltech Library

Letter

\title{
A Hybrid Catalyst-Bonded Membrane Device for Electrochemical Carbon Monoxide Reduction at Different Relative Humidities
}

Ian Sullivan, Lihao Han, Soo Hong Lee, Meng Lin, David Larson, Walter S. Drisdell, and Chengxiang Xiang

ACS Sustainable Chem. Eng., Just Accepted Manuscript • DOI: 10.1021/

acssuschemeng.9b04959 - Publication Date (Web): 20 Sep 2019

Downloaded from pubs.acs.org on September 20, 2019

\section{Just Accepted}

"Just Accepted" manuscripts have been peer-reviewed and accepted for publication. They are posted online prior to technical editing, formatting for publication and author proofing. The American Chemical Society provides "Just Accepted" as a service to the research community to expedite the dissemination of scientific material as soon as possible after acceptance. "Just Accepted" manuscripts appear in full in PDF format accompanied by an HTML abstract. "Just Accepted" manuscripts have been fully peer reviewed, but should not be considered the official version of record. They are citable by the Digital Object Identifier (DOI®). "Just Accepted" is an optional service offered to authors. Therefore, the "Just Accepted" Web site may not include all articles that will be published in the journal. After a manuscript is technically edited and formatted, it will be removed from the "Just Accepted" Web site and published as an ASAP article. Note that technical editing may introduce minor changes to the manuscript text and/or graphics which could affect content, and all legal disclaimers and ethical guidelines that apply to the journal pertain. ACS cannot be held responsible for errors or consequences arising from the use of information contained in these "Just Accepted" manuscripts. 


\title{
A Hybrid Catalyst-Bonded Membrane Device for Electrochemical
}

\section{Carbon Monoxide Reduction at Different Relative Humidities}

\author{
Ian Sullivan ${ }^{1}$, Lihao Han ${ }^{1}$, Soo Hong Lee ${ }^{2}$, Meng Lin $^{1}$, David M. Larson ${ }^{2}$, Walter S. Drisdell ${ }^{2 *}$, \\ and Chengxiang Xiang ${ }^{1 *}$ \\ 1 Joint Center for Artificial Photosynthesis, and Division of Chemistry and Chemical \\ Engineering, California Institute of Technology, 1200 E California Blvd. Pasadena, California \\ 91125, United States \\ ${ }^{2}$ Joint Center for Artificial Photosynthesis, and Chemical Sciences Division, Lawrence Berkeley \\ National Lab, 1 Cyclotron Rd. Berkeley, California, 94720, United States \\ Keywords: Gas Diffusion Electrode, Carbon Monoxide Reduction, Relative Humidity, \\ Multiphysics modeling, Vapor-fed, operando X-ray Absorption Spectroscopy.
}




\begin{abstract}
A hybrid catalyst-bonded membrane device using gaseous reactants for carbon monoxide reduction (COR) reaction in the cathode chamber, an aqueous electrolyte for oxygen evolution reaction (OER) in the anode chamber, and an anion exchange membrane (AEM) for product separation was modeled, constructed and tested. The $\mathrm{Cu}$ electrocatalyst was electrodeposited onto gas diffusion layers (GDLs) and was directly bonded to AEM by mechanical pressing in the hybrid device. The impacts of relative humidity at the cathode inlet on the selectivity and activity of COR were investigated by computational modeling and experimental methods. At a relative humidity of $30 \%$, the $\mathrm{Cu}$-based catalyst in the hybrid device exhibited a total operating current density of $87 \mathrm{~mA} \mathrm{~cm} \mathrm{~cm}^{-2}$ at $-2.0 \mathrm{~V}$ vs. $\mathrm{Ag} / \mathrm{AgCl}$ reference electrode, a Faradaic Efficiency (FE) for $\mathrm{C}_{2} \mathrm{H}_{4}$ generation of 32.6\%, and an FE for liquid-based carbon product of $42.6 \%$. Significant improvements in the partial current densities for COR were observed in relative to planar electrodes or flooded gas diffusion electrodes (GDEs). In addition, a custom test-bed was constructed to characterize the oxidation states of the $\mathrm{Cu}$ catalysts in real time along with product analysis though the backside of the GDLs via operando X-ray absorption (XAS) measurements.
\end{abstract}




\section{Introduction}

Gas diffusion electrodes (GDEs) have been recently used for the selective reduction of $\mathrm{CO}_{2}$ and $\mathrm{CO}$ to ethylene, ethanol, and other carbon products at high current densities and Faradaic efficiencies. ${ }^{1-8}$ GDE configurations, consisting of a three phase interface of reactant gas (CO or $\mathrm{CO}_{2}$ ), liquid or polymer electrolyte, and solid electrocatalyst have contributed to the improved performances due to increased concentration of reactant gas at the electrocatalyst surface compared to the limited solubility in liquid electrolytes. ${ }^{9}$ Vapor-fed GDEs also provide opportunities for the catalyst materials to operate under a wide range of $\mathrm{pH}$ conditions, and favorably steer selectivity through suppression of hydrogen evolution reaction (HER) by controlling the concentration of $\mathrm{CO}_{2}$ and water vapor. ${ }^{9}$ In comparison, while often operated at much lower current densities, traditional cells with bulk aqueous electrolytes are typically used to gain fundamental insights for reaction mechanisms under well-controlled conditions. ${ }^{10-16}$ $\mathrm{CO}$ is an important intermediate in $\mathrm{CO}_{2} \mathrm{R}$ and is widely accepted as the first intermediate to multi-carbon products. ${ }^{1,11,17,18} \mathrm{COR}$ not only has shed light on mechanistic pathways of $\mathrm{CO}_{2} \mathrm{R}$, but also has the advantage of producing an overall more efficient $\mathrm{CO}_{2} \mathrm{R}$ system in a two-step, cascade $\mathrm{CO}_{2}$ reactor, in which $\mathrm{CO}_{2}$ is first electrochemically reduced to $\mathrm{CO}$, followed by a second catalytic reactor in which $\mathrm{CO}$ is reduced to $\mathrm{C}_{2+}$ products such as ethanol, ethylene, or propanol. ${ }^{19}$ Using this approach could lead to a relative improvement in solar-to-fuel (STF) conversion efficiency as high as $54 \%$ in certain operating regions for the electrocatalysts. ${ }^{19,20}$ Herein, a hybrid catalyst-bonded membrane device that contains gas only reactants in the cathode chamber and a liquid electrolyte in the anode chamber, separated by an anion exchange membrane (AEM) was constructed, and the impacts of the applied potential and the relative humidity in this hybrid device configuration were studied. As most GDE configurations 
contained aqueous catholyte, we aim to investigate the impacts of water content in the GDE through controlling the relative humidity of vapor streams. Our goal was to optimize the water content to suppress HER while maintaining facile ionic conduction to the anode chamber. Unlike many previously reported flow cells, ${ }^{3,5,6,21,22}$ the electrodeposited $\mathrm{Cu}$ catalyst in the vapor-fed device was in direct physical contact with the AEM via mechanical pressing. In the hybrid device configuration, the AEM not only directly facilitates the ionic transport between the cathode and anode chamber, but also controls and dictates the local reaction environments at the reaction sites of the $\mathrm{Cu}$-catalyst for $\mathrm{COR}$. In a slightly modified cell configuration (See Supporting Information Figure S1), operando X-ray absorption spectroscopy (XAS) measurements were carried out at device relevant operating current densities to understand the impact of $\mathrm{Cu}$ oxidation state on the selectivity of reduced $\mathrm{CO}$ products. 


\section{Results and Discussion}

Figure 1a shows a schematic illustration of the hybrid catalyst-bonded membrane device. The hybrid catalyst-bonded membrane device consists of a cathode chamber and an anode chamber separated by an anion exchange membrane (AEM). In the anode chamber a flowing $1.0 \mathrm{M} \mathrm{KOH}$ aqueous electrolyte was used for oxygen evolution reaction (OER), while in the cathode chamber $\mathrm{CO}$ gas at a controlled relative humidity $(\mathrm{RH})$ was introduced at a flow rate of $10.0 \mathrm{sccm}$. The relative humidity of $\mathrm{CO}$ was controlled using two mass flow controllers, which controlled one dry stream, and one stream flowing through a bubbler filled with deionized water, as shown in the Supporting Information (Figure S2). Relative humidity, the ratio of the partial pressure of water to the equilibrium partial pressure of water, is given by Equation (1):

$$
R H=\frac{P_{H 2 O}}{P^{*} H 2 O}
$$

Where $\mathrm{P}_{\mathrm{H}_{2} \mathrm{O}}$ is the controlled partial pressure of water vapor, and $\mathrm{P}^{*} \mathrm{H}_{2} \mathrm{O}$ is the equilibrium partial pressure of water vapor at a given temperature. By controlling the individual flow rates of a fully humidified stream $(100 \% \mathrm{RH})$ and a dry stream $(0 \% \mathrm{RH})$ a range of $\mathrm{RH}$ can be achieved.

A traditional three-electrode configuration was used in the hybrid device with the $\mathrm{Cu}-\mathrm{GDE}$ as the working electrode, $\mathrm{Pt}$ mesh as the counter electrode, and $\mathrm{Ag} / \mathrm{AgCl}$ as the reference electrode. The $\mathrm{Pt}$ mesh was mechanically pressed against the AEM, and $\mathrm{Cu} / \mathrm{AEM} / \mathrm{Pt}$ formed the membrane-electrode-assembly (MEA) for COR in the hybrid device. As the cathode chamber does not contain any liquid electrolyte, the $\mathrm{Ag} / \mathrm{AgCl}$ reference electrode was placed in the anolyte reservoir (Fig. 1a). The non-traditional three-electrode configuration, in which the reference electrode was placed at the opposite of the counter electrode, was validated experimentally to provide accurate potential points for the working electrode (Figure S3). Total 
cell resistances measured before and after bulk electrolysis ranged from 2-5 $\Omega$ as measured by electrochemical impedance spectroscopy (EIS) (Figure S4).

The $\mathrm{Cu}$ electrocatalyst layer was electrodeposited on graphite-based gas diffusion layers (GDL) with a microporous carbon layer in an aqueous solution containing $0.15 \mathrm{M} \mathrm{CuCl}_{2}, 1.0 \mathrm{M} \mathrm{HCl}$, and $20 \%$ ethanol. Electrodepositions were performed potentiostatically by applying $-0.50 \mathrm{~V}$ vs. $\mathrm{Ag} / \mathrm{AgCl}$ until $4.5 \mathrm{C} \mathrm{cm}^{-2}$ of total charge was passed. During the deposition, the GDL served as the working electrode, copper mesh served as the counter electrode, and $\mathrm{Ag} / \mathrm{AgCl}$ (sat. $\mathrm{KCl}$ ) served as the reference electrode. After electrodeposition, the $\mathrm{Cu}-\mathrm{GDE}$ was dipped in deionized water several times to rinse off any residual deposition electrolyte, followed by drying in air. Figure $1 \mathrm{~b}$ shows an optical image of the electrodeposited $\mathrm{Cu}$ catalyst on GDL. The morphology and chemical composition of the $\mathrm{Cu}$ catalyst was characterized by scanning electron microscopy (SEM), energy dispersive X-ray spectroscopy (EDX), and X-ray diffraction (XRD) before and after deposition. Cross sectional SEM images (Figure 1c) of the Cu-GDE show a dendrite type morphology and the $\mathrm{Cu}$ catalyst mainly deposited on the surface of the GDL with no penetration into the microporous layer of the substrate as shown by SEM/EDX (Figure S5). High selectivity of $\mathrm{C}_{2} \mathrm{H}_{4}$ in GDEs has been largely attributed to $\mathrm{Cu}$ morphology, with nanoneedle and dendrite type morphologies resulting in high local $\mathrm{pH}$ environments amenable to $\mathrm{C}$ - $\mathrm{C}$ coupling. Polycrystalline $\mathrm{Cu}$ also results in the exposure of high index facets which also show increased selectivity for $\mathrm{C}_{2+}$ products. ${ }^{23-27}$ XRD patterns (Figure 1d) after deposition show peaks matching calculated polycrystalline $\mathrm{Cu}$ diffraction patterns, as well as a small amount of $\mathrm{Cu}_{2} \mathrm{O}$ present in the bulk.

Prior to bulk electrolysis experiments the $\mathrm{Cu}-\mathrm{GDE}$ was allowed to equilibrate under a flow of $\mathrm{CO}(10 \mathrm{sccm})$ at room temperature and controlled $\mathrm{RH}$ for 1 hour at open circuit voltage (OCV) 
conditions. During this period of time EIS measurements were taken to determine the cell resistance, and it was found over the course of an hour that the OCV typically changed from -0.2 $\mathrm{V}$ to $-1.0 \mathrm{~V}$, while the cell resistance reduced from $\sim 30 \Omega$ to $\sim 4 \Omega$ at equilibration due to wetting of the anion exchange membrane (Figure S6). Bulk electrolysis experiments were performed using a range of potentials from $-1.6 \mathrm{~V}$ to $-2.2 \mathrm{~V}$ vs. $\mathrm{Ag} / \mathrm{AgCl}$. Gas products from $\mathrm{COR}$ were measured every 6 min during bulk electrolysis by gas chromatograph (GC) (see SI for more details), while liquid products were collected after bulk electrolysis from the anode electrolyte and measured by high performance liquid chromatograph (HPLC). We note that the liquid products identified in the HPLC may not be the direct reduction products of the Cu catalyst in the hybrid device, since the Pt anode could oxidize some liquid products that transported across the AEM. Additional loss of liquid products may have resulted from escaping the cathode or anode chamber in the vapor form or being absorbed within the AEM. Nevertheless, from almost all measurements, $>85 \%$ of electrons participating the reactions were accounted for COR products using GC and HPLC. Figure 2a shows the total operating current densities as a function of time at $100 \% \mathrm{RH}$. The total current densities increased for the first 5-10 minutes of operation and reached a relatively steady value after $\sim 20$ minutes of operation. Figure $2 b$ shows the corresponding product distribution as a function of applied potentials for COR at $100 \%$ RH. At $2.0 \mathrm{~V}$ vs. $\mathrm{Ag} / \mathrm{AgCl}$, a total carbon product selectivity of $51.1 \%$ (23.5\% toward generation of $\mathrm{C}_{2} \mathrm{H}_{4}$, and $27.6 \%$ toward generation of liquid based carbon products) was observed. The geometric partial current densities for $\mathrm{C}_{2} \mathrm{H}_{4}$ generation remained relatively stable between $30 \mathrm{~mA}$ $\mathrm{cm}^{-2}$ to $35 \mathrm{~mA} \mathrm{~cm}$-2 during the course of testing for COR (Fig. 2c). In comparison, aqueous-based electrolytes exhibit geometric partial current densities $<1 \mathrm{~mA} \mathrm{~cm}^{-2}$ for COR due to the low solubility and low diffusion coefficient of $\mathrm{CO}$, even with a range of catalyst morphologies and 
nano-structures. ${ }^{13-16}$ The low partial current density in cells with bulk aqueous electrolytes can be simply explained by Fick's law of diffusion (Equation 2) in which $\mathrm{j}$ is the partial current density, $\mathrm{n}$ is the number of electrons involved in the electrochemical reduction step (4 for $2 \mathrm{CO}$ to $\left.\mathrm{C}_{2} \mathrm{H}_{4}\right), D_{0}$ is the diffusion coefficient $\left(2 \times 10^{-9} \mathrm{~m}^{2} \mathrm{~s}^{-1}\right.$ at $\left.20^{\circ} \mathrm{C}\right)$ and $C_{0}$ is the solubility of $\mathrm{CO}$ in aqueous solution $\left(1 \mathrm{mM}\right.$ at $\left.20{ }^{\circ} \mathrm{C}\right), L$ is the hydrodynamic boundary layer thickness, and $\mathrm{F}$ is Faraday's constant $\left(96485 \mathrm{C} \mathrm{mol}^{-1}\right)$. The mass transport limited current density for CO reduction to $\mathrm{C}_{2} \mathrm{H}_{4}$ was limited to $\sim 0.81 \mathrm{~mA} \mathrm{~cm}^{-2}$ at a boundary layer thickness of $\sim 100 \mu \mathrm{m}$.

$$
j=n F D_{o} \frac{c_{o}}{L}
$$

Figure 2c also shows the geometric partial current density for a flooded GDE, in which the $\mathrm{Cu}$ catalyst layer was intentionally flooded with $\mathrm{KOH}$ electrolyte ahead of the bulk electrolysis measurements. The partial current density for $\mathrm{C}_{2} \mathrm{H}_{4}$ generation reduced to $\sim 1-2 \mathrm{~mA} \mathrm{~cm}{ }^{-2}$, which was comparable in value to many reported aqueous-based systems. In the flooded GDE, the catalyst layer was fully immersed in aqueous $\mathrm{KOH}$ electrolyte, which resulted in the disruption of three-phase interfaces that were responsible for the facile vapor $\mathrm{CO}$ transport to the catalytic sites. The flooded GDE, in which the reactant $\mathrm{CO}$ needed to transport through hundreds of micrometers of liquid layer, essentially reduced into a high surface area, nano-structured electrode that operated in a bulk aqueous electrolyte, resulting in significant decrease in partial current density for COR, as well as larger partial current densities and Faradaic efficiencies for HER (Figure S14).

The impacts of relative humidity on the activity and selectivity of the $\mathrm{Cu}-\mathrm{GDE}$ were carried out by experiment and by Multi-physics simulations. Figure 3a shows the linear sweep voltammetry (LSV) of $\mathrm{Cu}-\mathrm{GDEs}$ at five different RHs from $\mathrm{OCV}$ to $-2.2 \mathrm{~V}$ vs. $\mathrm{Ag} / \mathrm{AgCl}$ reference electrode at a scan rate of $50 \mathrm{mV} \mathrm{s}^{-1}$. The total operating current density exhibited an increasing trend as the 
RH increased from $5 \%$ to $100 \%$. Current densities up to $350 \mathrm{~mA} \mathrm{~cm}-2$ were observed at $-3.0 \mathrm{~V}$ vs. $\mathrm{Ag} / \mathrm{AgCl}$ (Fig. S7), however at these high current density regions, the intense OER at the anode chamber, which was not optimized for this study, produced large amounts of $\mathrm{O}_{2}$ bubbles and caused noisy electrochemical signals. Figure $3 b, 3 c$ and $3 d$ show the product distributions of COR at various applied potentials for three different RH conditions. The applied potential had the largest impact on product distribution and in general, high selectivity for COR products were observed at more negative potentials, with the highest selectivity of total COR products of $\sim 75 \%$ at $-2.0 \mathrm{~V}$ and $\mathrm{RH} 30 \%$. Product distributions were impacted in the $\mathrm{RH}$ range of $5 \%$ to $30 \%$, with little change in the distribution at $\mathrm{RH}$ values $>50 \%$ (Figure $\mathrm{S} 8$ ). Control experiments using a $\mathrm{N}_{2}$ stream resulted in $>90 \%$ Faradaic efficiency for HER with no liquid products detected by HPLC (Figure S9). The major liquid product distribution consisted of acetate, ethanol, and propanol; with trace amounts of acetylaldehyde and ethylene glycol detected. As liquid products were formed and diffused across the AEM, they could be electrochemically oxidized to other products. Ethanol has been electrochemically oxidized in basic media to several products including acetate, acetylaldehyde, and $\mathrm{CO}_{2} \cdot{ }^{28-30}$ To determine the extent to which ethanol could be oxidized to any of these products, a control experiment was performed by spiking the anolyte with $1000 \mathrm{ppm}$ ethanol with bulk electrolysis performed under $\mathrm{N}_{2}$ flow. After $1 \mathrm{~h}$ of electrolysis at $-2.2 \mathrm{~V}$, the anolyte was analyzed by HPLC and it was found that the ethanol signal was significantly decreased, while the acetate signal increased significantly. Based on the stoichiometry, we calculated $22.8 \%$ of ethanol was oxidized to acetate, $35.3 \%$ to $\mathrm{CO}_{2}$, while 41.9\% remained. Due to the complexity of the oxidation of COR products in the anode chamber, we cannot currently determine if the catalyst was directly responsible for the generation of acetate, or if the catalyst is selective for ethanol alone, which is then oxidized to acetate. 
The relatively small change in the activity and selectivity for COR at various RHs at the cathode feed was investigated by a Multi-physics model that accounted for vapor and water transport in the vapor-fed test-bed. Figure 4a shows a schematic illustration of the vapor-fed testbed in Multi-physics modeling, with the calculation domain of the $2 \mathrm{D}$ model for water-vapor transport available in the Supporting Information file. In the AEM domain, three mechanisms of the water transport were considered in the model, including diffusion, water electro-osmotic drag, and hydraulic permeation. The liquid-gas flow in GDL, MPL, and channel domains were described by two separate Darcy's equations for liquid phase and gas phase, respectively. The water saturation was predicted using Van Genuchten model which was expressed as capillary pressure. The Hertz-Knudsen-Langmuir equation was used to predict the interfacial mass transfer (evaporation and condensation) between liquid and gas phase. ${ }^{31}$ The $2 \mathrm{D}$ numerical model was used to simulate local RH and water saturation in the catalyst layer as a function of the relative humidity at the cathode inlet. Figure $4 \mathrm{~b}$ shows the average $\mathrm{RH}$ inside the cathode catalyst layer ranged from $88.5 \%$ to $99.3 \%$ while the external $\mathrm{RH}$ was controlled from $5 \%$ to $100 \%$. The water saturation in the cathode catalyst layer was close to 0.52 regardless of controlled inlet RH. This is mostly related to the domination of water transport through the AEM by diffusion due to the aqueous-based electrolyte in the anode compartment. The relatively unchanged local RH and water saturation in the catalyst layer resulted in limited impact to activity and selectivity for COR by changing the inlet $\mathrm{RH}$ in the system. To further test this hypothesis, an all vapor fed two-electrode configuration was employed by flowing $100 \% \mathrm{RH} \mathrm{N}_{2}$ through the anode at $10.0 \mathrm{sccm}$, and $5 \% \mathrm{RH} \mathrm{CO}$ in the cathode. The current density was set to $10 \mathrm{~mA} / \mathrm{cm}^{2}$, the average current density when applying $-1.6 \mathrm{~V}$ in a three-electrode configuration. While the Faradaic efficiency of HER was diminished to $7.5 \%$ in this all vapor configuration, the anion 
exchange membrane would dry out over a short period of time resulting in large cell resistances and increased cell voltages (Figure S10). Further improvements to water transport and controlling RH at the anode could lead to decreased HER and better selectivity of COR products.

A slightly modified GDE cell with an opening for incident X-rays was constructed to accommodate operando XAS measurements. Figure 5a shows the experimental setup for operando XAS measurements at the Stanford Synchrotron Radiation Lightsource (SSRL). Multiple $\mathrm{Cu}$ oxidation states were observed by XANES measurements after deposition and during $\mathrm{OCV}$ conditions, and as the $\mathrm{Cu}-\mathrm{GDE}$ was allowed to equilibrate an increase in the $\mathrm{Cu}_{2} \mathrm{O}$ pre-edge was observed by XANES (Figure S11). There are several factors to consider during this equilibration period, including membrane wetting and oxidation state changes of the electrocatalyst which all play factors in the observed changes. The change in OCV correlates to the chemical oxidation state change of the $\mathrm{Cu}-\mathrm{GDE}$ when exposed to a $\mathrm{CO}$ environment, while under $\mathrm{N}_{2}$ flow, no significant change of OCV was observed (Figure S6). The decreased cell resistance is due to membrane wetting resulting in increased conductivity of the membrane. Figure $5 \mathrm{~b}$ and $5 \mathrm{c}$ show the XANES measurements of the $\mathrm{Cu}-\mathrm{GDEs}$ at $\mathrm{OCV}$ and under various applied potentials for COR. Under OCV conditions, a mixed oxidation state of $\mathrm{Cu}$ was observed (Figure 2b) with peaks matching both $\mathrm{Cu}$ and $\mathrm{Cu}_{2} \mathrm{O}$ reference XANES spectra. However, during bulk electrolysis the $\mathrm{Cu}$ oxide was eventually reduced and peaks from the $\mathrm{Cu}-\mathrm{GDE}$ matched the metallic $\mathrm{Cu}$ standard (Figure 5c). As $\mathrm{Cu}$ oxides are only observed at OCV conditions and metallic $\mathrm{Cu}$ is observed at every potential tested, we conclude that metallic $\mathrm{Cu}$, instead of $\mathrm{Cu}$ oxides, was responsible for catalytic COR in the vapor-fed GDEs based on XANES measurements, in agreement with previous operando reports. ${ }^{32}$ The vapor-fed GDEs offered a unique platform, without the complications in the aqueous electrolyte, for investigating chemical 
and structural properties of the catalyst under device-relative operating conditions. In aqueous based cells, high current densities may result in bubble formation at the electrode surface blocking active sites and disrupting the operando measurements. However, in the vapor-fed configuration there is no liquid at the electrode surface and only water vapor is needed. This enables spectroscopic probing of the system at relatively high current density with little interference. 


\section{Conclusion}

In summary, we report a hybrid catalyst-bonded membrane device using only gas reactants for the electrochemical reduction of $\mathrm{CO}$ to ethylene, and various liquid products with a selectivity of up to $75 \%$ for $\mathrm{C}_{2+}$ products. The identified liquid products included acetate, ethanol, and propanol. At a relative humidity of $30 \%$, the $\mathrm{Cu}$-based catalyst in the hybrid device configuration exhibited a total operating current density of $87 \mathrm{~mA} \mathrm{~cm} \mathrm{~cm}^{-2}$ at $-2.0 \mathrm{~V}$ vs. $\mathrm{Ag} / \mathrm{AgCl}$ reference electrode, a Faradaic Efficiency (FE) for $\mathrm{C}_{2} \mathrm{H}_{4}$ generation of $32.6 \%$, and a $\mathrm{FE}$ for liquid based carbon product of $42.6 \%$ for CO reduction. Significant improvements in the partial current densities for COR were observed relative to planar electrodes or flooded gas diffusion electrodes (GDEs). The local RH and water saturation at the catalyst layer were dictated by the diffusional water transport through the AEM and exhibited little change over a wide range of the cathode vapor feed from $5 \%$ to $100 \%$. As a result, relative humidity at the cathode had little impact on the product selectivity and activity in the hybrid catalyst-bonded membrane device. In addition, while different oxidation states of $\mathrm{Cu}$ were observed by operando XAS measurements in a custom test-bed, these were quickly reduced to metallic $\mathrm{Cu}$ and had no direct correlation on the selectivity of ethylene or $\mathrm{H}_{2}$. 
Supporting Information: Detailed descriptions of the $\mathrm{Cu}$ electrodepositon, cell design, cross sectional SEM/EDX data, relative humidity control schematic, details for numerical modelling for water-vapor transport, cell resistance before and after bulk electrolysis, CV scans of ferrocyanide in a GDE configuration, OCV and EIS data during equilibration, XANES data at equilibration, and SEM images before and after bulk electrolysis, can be found in the Supporting Information file.

Acknowledgements: This material is based on work performed by the Joint Center for Artificial Photosynthesis, a DOE Energy Innovation Hub, supported through the Office of Science of the U.S. Department of Energy under Award Number DE-SC0004993. Use of the Stanford Synchrotron Radiation Lightsource, SLAC National Accelerator Laboratory, is supported by the U.S. Department of Energy, Office of Science, Office of Basic Energy Sciences under Contract No. DE-AC02-76SF00515. 

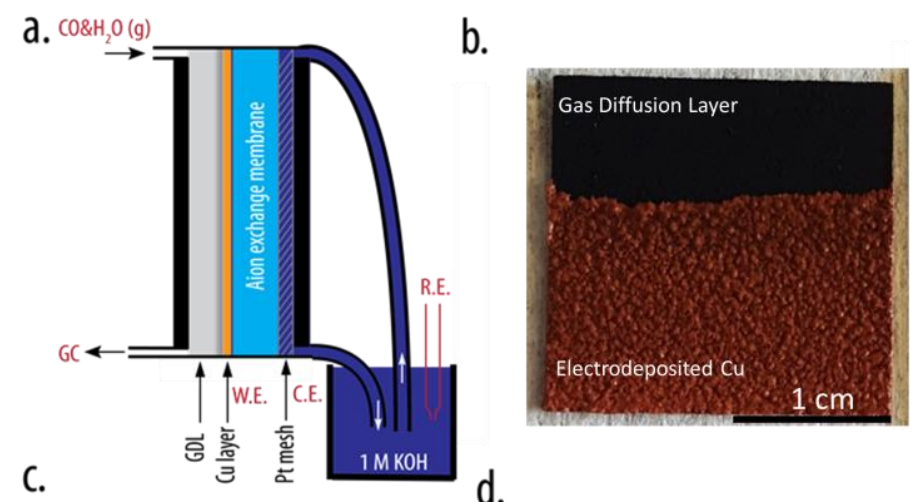

d.
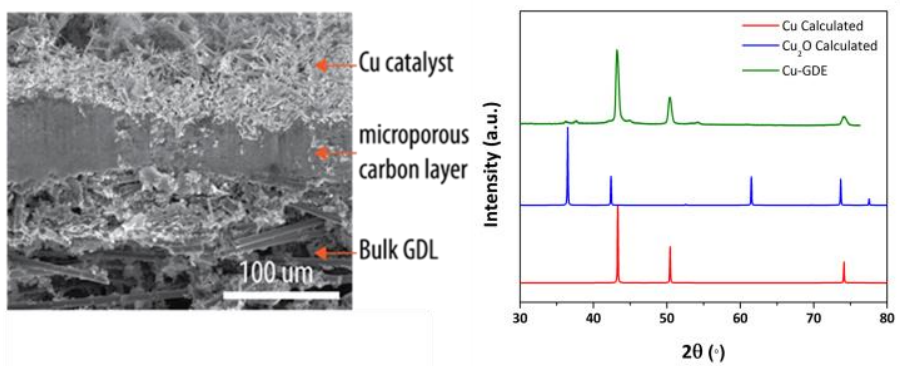

Figure 1. (a) A schematic illustration of the hybrid catalyst-bonded membrane device. (b) Optical image of the electrodeposited $\mathrm{Cu}$ catalysts on GDL. (c) Cross sectional SEM images of the $\mathrm{Cu}$ catalysts on GDL. (d) XRD pattern of the electrodeposited Cu catalyst on GDL. 

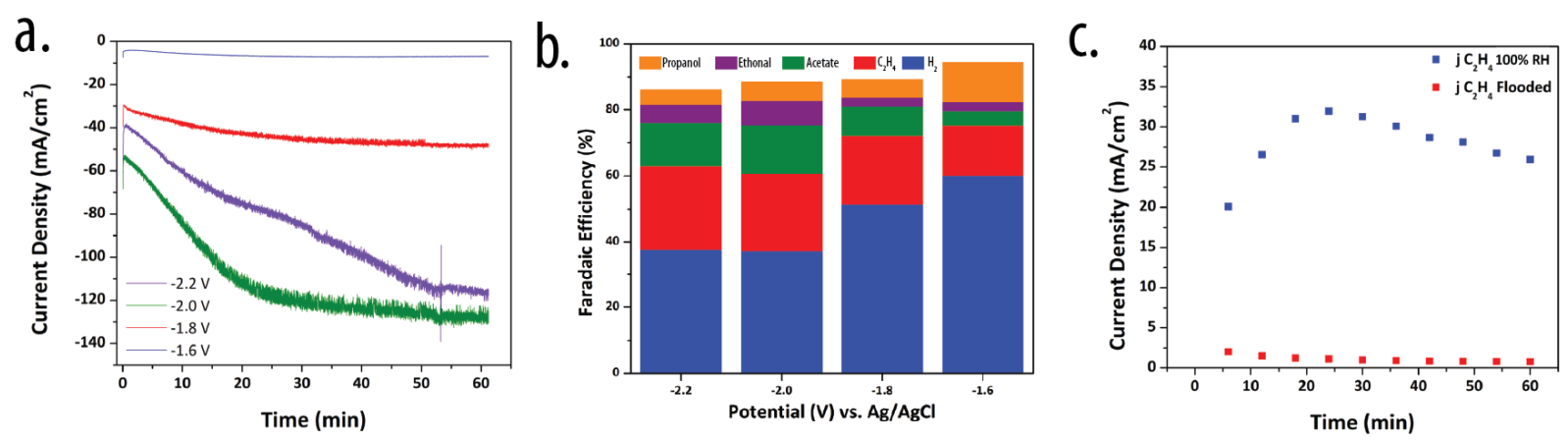

Figure 2. (a) Total operating current densities as a function of time at different applied potentials for COR at $100 \%$ RH. (b) Product distribution as a function of applied potentials for COR at $100 \%$ RH. (c) Partial current densities for $\mathrm{C}_{2} \mathrm{H}_{4}$ generation at $-2.0 \mathrm{~V}$ as a function of time for the flooded cell and the vapor cell at $100 \% \mathrm{RH}$. 
a.

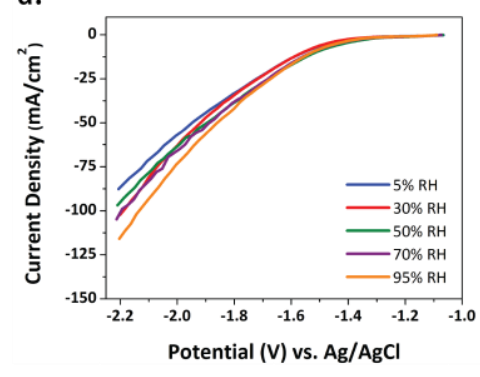

C.

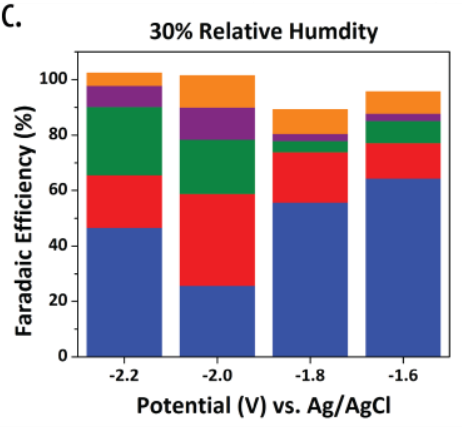

Propanol Ethanol

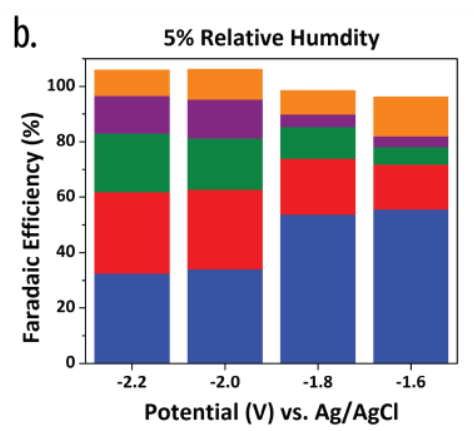

d.

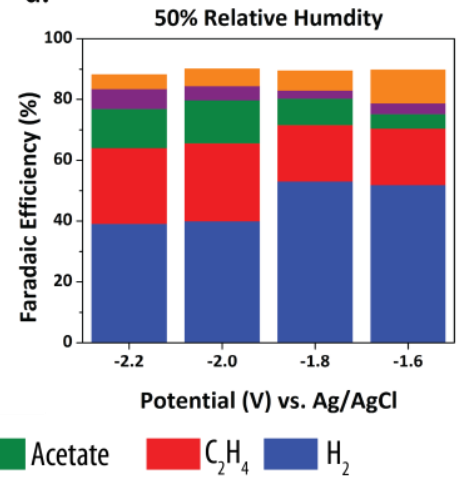

Figure 3. (a) LSV scans of Cu-GDE at various relative humidities. (b)-(d) Product distribution after $1 \mathrm{~h}$ bulk electrolysis as a function of applied potential and controlled relative humidity for COR. 

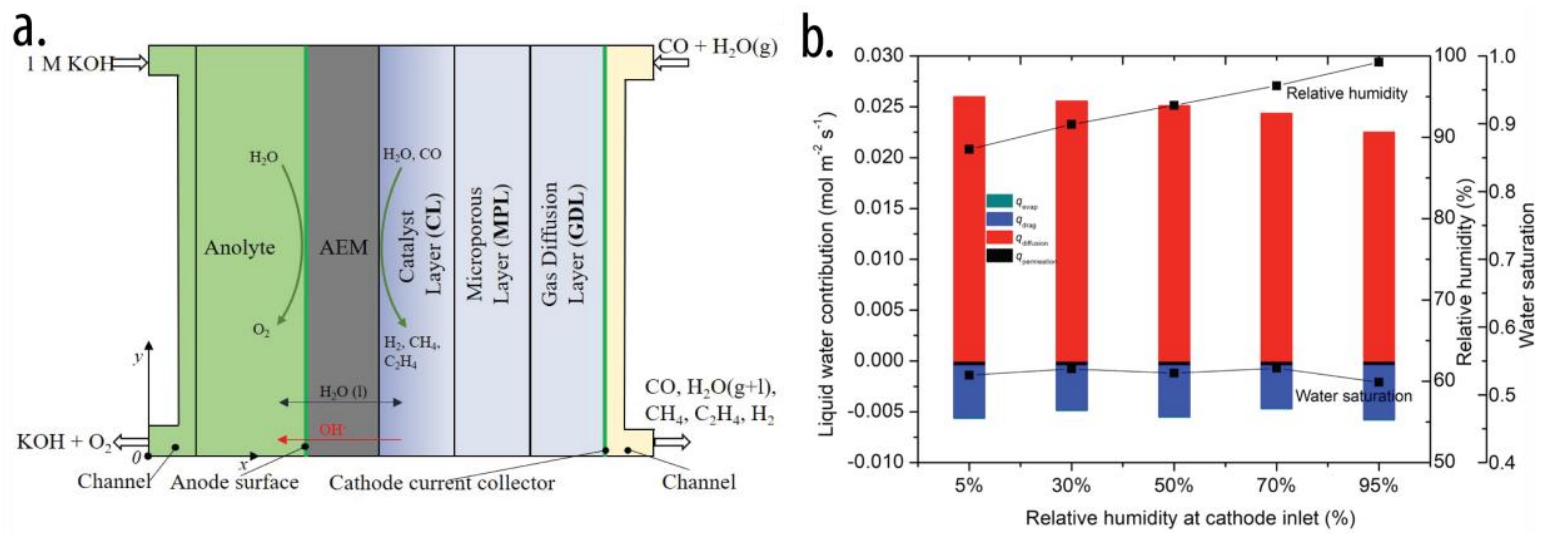

Figure 4. (a) A schematic illustration of the vapor-fed device in Multi-physics modeling (b) Simulated average relative humidity and water saturation in the cathode catalyst layer. 
a.

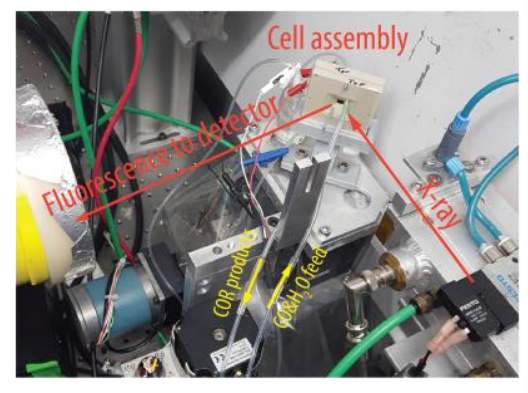

b.

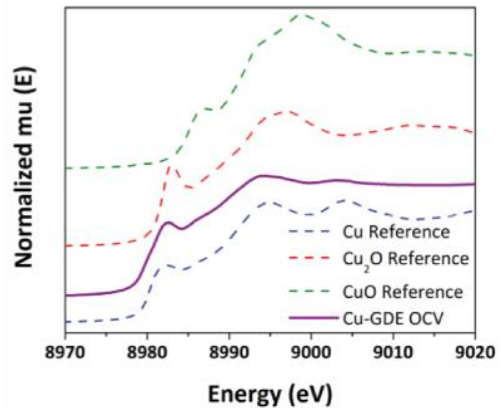

C.

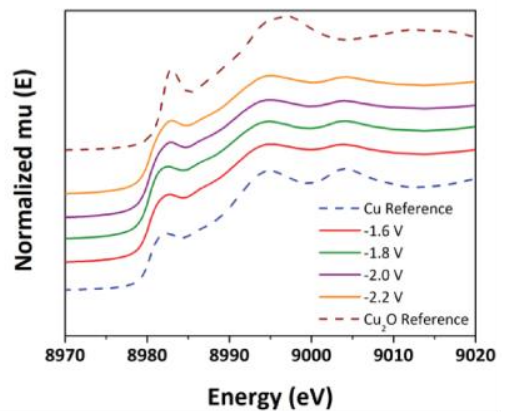

Figure 5. (a) Experimental setup for Operando XAS at SSRL (b) Operando XANES measurements at $\mathrm{OCV}$ and (c) under various applied potentials. 


\section{$\underline{\text { References }}$}

(1) Ma, S.; Sadakiyo, M.; Luo, R.; Heima, M.; Yamauchi, M.; Kenis, P. J. A. One-Step Electrosynthesis of Ethylene and Ethanol from $\mathrm{CO}_{2}$ in an Alkaline Electrolyzer. J. Power Sources 2016, 301, 219-228, DOI j.jpowsour.2015.09.124.

(2) Hoang, T. T. H.; Verma, S.; Ma, S.; Fister, T. T.; Timoshenko, J.; Frenkel, A. I.; Kenis, P. J. A.; Gewirth, A. A. Nanoporous Copper-Silver Alloys by Additive-Controlled Electrodeposition for the Selective Electroreduction of $\mathrm{CO}_{2}$ to Ethylene and Ethanol. $J$. Am. Chem. Soc. 2018, 140, 5791-5797, DOI 10.1021/jacs.8b01868.

(3) Kim, B.; Hillman, F.; Ariyoshi, M.; Fujikawa, S.; Kenis, P. J. A. Effects of Composition of the Micro Porous Layer and the Substrate on Performance in the Electrochemical Reduction of $\mathrm{CO}_{2}$ to CO. J. Power Sources 2016, 312, 192-198, DOI 10.1016/j.jpowsour.2016.02.043.

(4) Whipple, D. T.; Finke, E. C.; Kenis, P. J. A. Microfluidic Reactor for the Electrochemical Reduction of Carbon Dioxide: The Effect of pH. Electrochem. Solid-State Lett. 2010, 13, B109-B111, DOI 10.1149/1.3456590.

(5) Dinh, C.-T.; Burdyny, T.; Kibria, M. G.; Seifitokaldani, A.; Gabardo, C. M.; García de Arquer, F. P.; Kiani, A.; Edwards, J. P.; De Luna, P.; Bushuyev, O. S.; et al. $\mathrm{CO}_{2}$ Electroreduction to Ethylene via Hydroxide-Mediated Copper Catalysis at an Abrupt Interface. Science 2018, 360, 783-787, DOI 10.1126/science.aas9100.

(6) De Luna, P.; Quintero-Bermudez, R.; Dinh, C.-T.; Ross, M. B.; Bushuyev, O. S.; Todorović, P.; Regier, T.; Kelley, S. O.; Yang, P.; Sargent, E. H. Catalyst ElectroRedeposition Controls Morphology and Oxidation State for Selective Carbon Dioxide Reduction. Nat. Catal. 2018, 1, 103-110, DOI 10.1038/s41929-017-0018-9.

(7) Zhuang, T. T.; Liang, Z. Q.; Seifitokaldani, A.; Li, Y.; De Luna, P.; Burdyny, T.; Che, F.; Meng, F.; Min, Y.; Quintero-Bermudez, R.; et al. Steering Post-C-C Coupling Selectivity Enables High Efficiency Electroreduction of Carbon Dioxide to Multi-Carbon Alcohols. Nat. Catal. 2018, 1, 421-428, DOI 10.1038/s41929-018-0084-7.

(8) Ripatti, D. S.; Veltman, T. R.; Kanan, M. W. Carbon Monoxide Gas Diffusion Electrolysis That Produces Concentrated $\mathrm{C}_{2}$ Products with High Single-Pass Conversion. Joule 2019, 3, 240-256, DOI j.joule.2018.10.007.

(9) Higgins, D.; Hahn, C.; Xiang, C.; Jaramillo, T. F.; Weber, A. Z. Gas-Diffusion Electrodes for Carbon Dioxide Reduction: A New Paradigm. ACS Energy Lett. 2019, 4, 317-324, DOI 10.1021/acsenergylett.8b02035.

(10) Hori, Y. Electrochemical CO 2 Reduction on Metal Electrodes. In Modern Aspects of Electrochemistry; Vayenas, C., Ed.; Springer: New York, 2008; pp 89-189.

(11) Kuhl, K. P.; Cave, E. R.; Abram, D. N.; Jaramillo, T. F. New Insights into the Electrochemical Reduction of Carbon Dioxide on Metallic Copper Surfaces. Energy Environ. Sci. 2012, 5, 7050-7059, DOI 10.1039/c2ee21234j.

(12) Lum, Y.; Cheng, T.; Goddard, W. A.; Ager, J. W. Electrochemical CO Reduction Builds 
Solvent Water into Oxygenate Products. J. Am. Chem. Soc. 2018, 140, 9337-9340, DOI 10.1021/jacs.8b03986.

(13) Hori, Y.; Takahashi, R.; Yoshinami, Y.; Murata, A. Electrochemical Reduction of CO at a Copper Electrode. J. Phys. Chem. B 1997, 101, 7075-7081, DOI 10.1021/jp970284i.

(14) Feng, X.; Jiang, K.; Fan, S.; Kanan, M. W. A Direct Grain-Boundary-Activity Correlation for CO Electroreduction on Cu Nanoparticles. ACS Cent. Sci. 2016, 2, 169-174, DOI 10.1021/acscentsci.6b00022.

(15) Li, C. W.; Ciston, J.; Kanan, M. W. Electroreduction of Carbon Monoxide to Liquid Fuel on Oxide-Derived Nanocrystalline Copper. Nature 2014, 508, 504-507, DOI 10.1038/nature13249.

(16) Verdaguer-Casadevall, A.; Li, C. W.; Johansson, T. P.; Scott, S. B.; McKeown, J. T.; Kumar, M.; Stephens, I. E. L.; Kanan, M. W.; Chorkendorff, I. Probing the Active Surface Sites for CO Reduction on Oxide-Derived Copper Electrocatalysts. J. Am. Chem. Soc. 2015, 137, 9808-9811, DOI 10.1021/jacs.5b06227.

Shah, A. H.; Wang, Y.; Woldu, A. R.; Lin, L.; Iqbal, M.; Cahen, D.; He, T. Revisiting Electrochemical Reduction of $\mathrm{CO}_{2}$ on Cu Electrode: Where Do We Stand about the Intermediates? J. Phys. Chem. C 2018, 122, 18528-18536, DOI 10.1021/acs.jpcc.8b05348.

(18) Schouten, K. J. P.; Kwon, Y.; Van Der Ham, C. J. M.; Qin, Z.; Koper, M. T. M. A New Mechanism for the Selectivity to $\mathrm{C}_{1}$ and $\mathrm{C}_{2}$ species in the Electrochemical Reduction of Carbon Dioxide on Copper Electrodes. Chem. Sci. 2011, 2, 1902-1909, DOI 10.1039/c1sc00277e.

(19) Zhou, X.; Xiang, C. Comparative Analysis of Solar-to-Fuel Conversion Efficiency: A Direct, One-Step Electrochemical $\mathrm{CO}_{2}$ Reduction Reactor versus a Two-Step, Cascade Electrochemical $\mathrm{CO}_{2}$ Reduction Reactor. ACS Energy Lett. 2018, 3, 1892-1897, DOI acsenergylett.8b01077.

(20) Gurudayal; Perone, D.; Malani, S.; Lum, Y.; Haussener, S.; Ager, J. W. Sequential Cascade Electrocatalytic Conversion of Carbon Dioxide to $\mathrm{C}-\mathrm{C}$ Coupled Products. ACS Appl. Energy Mater. 2019, 2, 4551-4559, DOI 10.1021/acsaem.9b00791.

(21) Han, L.; Zhou, W.; Xiang, C. High-Rate Electrochemical Reduction of Carbon Monoxide to Ethylene Using Cu-Nanoparticle-Based Gas Diffusion Electrodes. ACS Energy Lett. 2018, 3, 855-860, DOI 10.1021/acsenergylett.8b00164.

(22) Jouny, M.; Luc, W.; Jiao, F. High-Rate Electroreduction of Carbon Monoxide to MultiCarbon Products. Nat. Catal. 2018, 1, 748-755, DOI 10.1038/s41929-018-0133-2.

(23) Le, M.; Ren, M.; Zhang, Z.; Sprunger, P. T.; Kurtz, R. L.; Flake, J. C. Electrochemical Reduction of $\mathrm{CO}_{2}$ to $\mathrm{CH}_{3} \mathrm{OH}$ at Copper Oxide Surfaces. J. Electrochem. Soc. 2011, 158, E45-E49, DOI 10.1149/1.3561636.

(24) Mi, Y.; Peng, X.; Liu, X.; Luo, J. Selective Formation of $\mathrm{C}_{2}$ Products from Electrochemical $\mathrm{CO}_{2}$ Reduction over $\mathrm{Cu}_{1.8 \mathrm{Se}}$ Nanowires. ACS Appl. Energy Mater. 2018, 1, 5119-5123, DOI 10.1021/acsaem.8b00744. 
(25) Huo, Y.; Peng, X.; Liu, X.; Li, H.; Luo, J. High Selectivity Toward $\mathrm{C}_{2} \mathrm{H}_{4}$ Production over $\mathrm{Cu}$ Particles Supported by Butterfly-Wing-Derived Carbon Frameworks. ACS Appl. Mater. Interfaces 2018, 10, 12618-12625, DOI 10.1021/acsami.7b19423.

(26) Baricuatro, J. H.; Kim, Y.-G.; Korzeniewski, C. L.; Soriaga, M. P. Seriatim ECSTMECPMIRS of the Adsorption of Carbon Monoxide on $\mathrm{Cu}(100)$ in Alkaline Solution at $\mathrm{CO}_{2}$ Reduction Potentials. Electrochem. commun. 2018, 91, 1-4, DOI 10.1016/j.elecom.2018.04.016.

(27) Raciti, D.; Cao, L.; Livi, K. J. T.; Rottmann, P. F.; Tang, X.; Li, C.; Hicks, Z.; Bowen, K. H.; Hemker, K. J.; Mueller, T.; et al. Low-Overpotential Electroreduction of Carbon Monoxide Using Copper Nanowires. ACS Catal. 2017, 7, 4467-4472, DOI 10.1021/acscatal.7b01124.

(28) Barbosa, A. F. B.; Oliveira, V. L.; van Drunen, J.; Tremiliosi-Filho, G. Ethanol ElectroOxidation Reaction Using a Polycrystalline Nickel Electrode in Alkaline Media: Temperature Influence and Reaction Mechanism. J. Electroanal. Chem. 2015, 746, 31-38, DOI 10.1016/j.jelechem.2015.03.024.

(29) Puthiyapura, V. K.; Lin, W. F.; Russell, A. E.; Brett, D. J. L.; Hardacre, C. Effect of Mass Transport on the Electrochemical Oxidation of Alcohols Over Electrodeposited Film and Carbon-Supported Pt Electrodes. Top. Catal. 2018, 61, 240-253 DOI 10.1007/s11244018-0893-6.

(30) Guillén-Villafuerte, O.; García, G.; Arévalo, M. C.; Rodríguez, J. L.; Pastor, E. New Insights on the Electrochemical Oxidation of Ethanol on Carbon-Supported Pt Electrode by a Novel Electrochemical Mass Spectrometry Configuration. Electrochem. commun. 2016, 63, 48-51, DOI 10.1016/j.elecom.2015.12.007.

(31) Schulz, V. P.; Becker, J.; Wiegmann, A.; Mukherjee, P. P.; Wang, C.-Y. Modeling of Two-Phase Behavior in the Gas Diffusion Medium of PEFCs via Full Morphology Approach. J. Electrochem. Soc. 2007, 154, B419-B426, DOI 10.1149/1.2472547.

(32) Scott, S. B.; Hogg, T. V.; Landers, A. T.; Maagaard, T.; Bertheussen, E.; Lin, J. C.; Davis, R. C.; Beeman, J. W.; Higgins, D.; Drisdell, W. S.; et al. Absence of Oxidized Phases in $\mathrm{Cu}$ under CO Reduction Conditions. ACS Energy Lett. 2019, 4, 803-804, DOI 10.1021/acsenergylett.9b00172. 
For Table of Contents Use Only
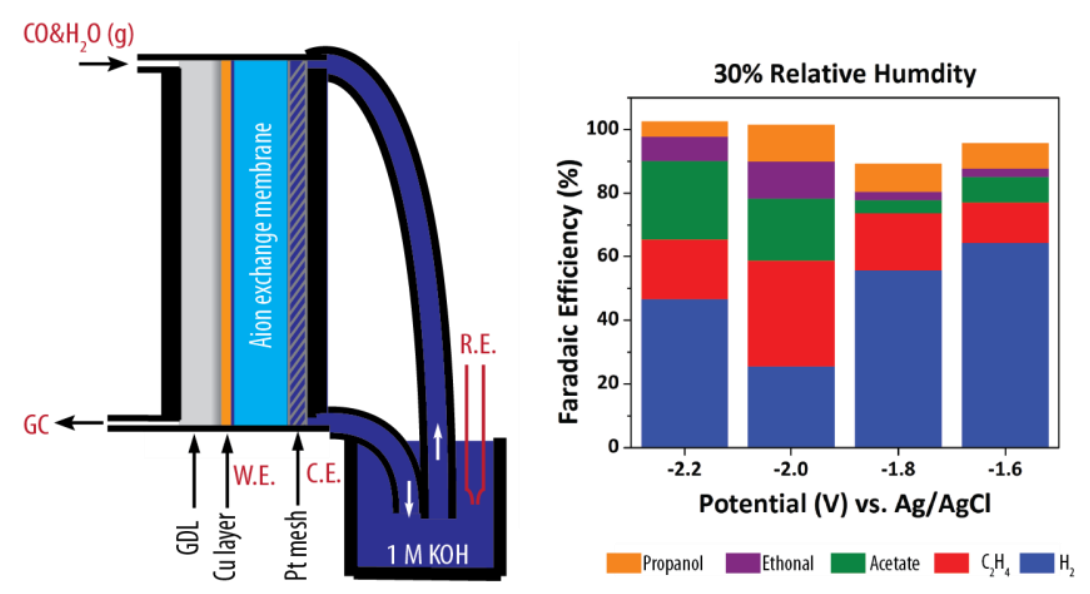

Synopsis: Modeling and experimental study of a hybrid catalyst-bonded membrane device for electrochemical carbon monoxide reduction at different relative humidities. 


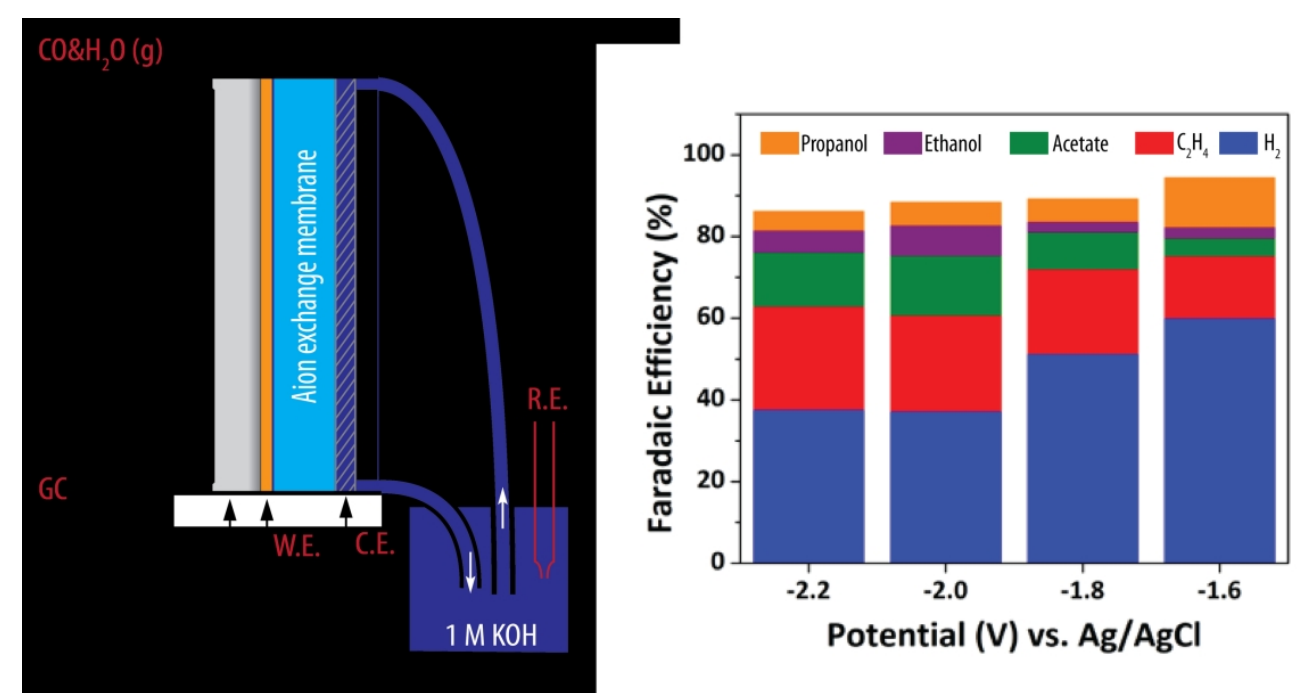

Synopsis: Modeling and experimental study of a hybrid catalyst-bonded membrane device for electrochemical carbon monoxide reduction at different relative humidities.

$210 \times 109 \mathrm{~mm}(300 \times 300 \mathrm{DPI})$ 